\title{
Extraction of bituminous material from fossil organic matter using liquid carbon dioxide under liquid-vapour equilibrium conditions
}

\author{
F. Martin*, T. Verdejo and F. J. González-Vila \\ Instituto de Recursos Naturales y Agrobiologia, C.S.I.C., Apartado 1052, 41080 Seville (Spain)
}

\begin{abstract}
Extracts from a peat, a low-rank coal and a bituminous oil shale obtained with liquid carbon dioxide were studied by capillary gas chromatography-mass spectrometry and compared with those obtained by Soxhlet extraction with $n$-hexane. Although the extraction yields with liquid carbon dioxide were lower, the composition of the extracts, comprising mainly a large variety of linear and cyclic hydrocarbons, was similar in both cases. Owing to the advantages of the liquid carbon dioxide extraction regarding speed, cleanliness and mildness of the extraction conditions, it seems to be an adequate procedure, coupled with gas chromatography-mass spectrometry, to study the biomarker composition of sedimentary organic matter.
\end{abstract}

\section{INTRODUCTION}

Soxhlet and sonication techniques have until now been the most widely used methods for extracting the bituminous fractions of sedimentary organic matter. The study of these extracts by chromatographic methods is the basis of the "biomarker technique", i.e. the isolation and characterization of biochemical products in geological samples, which can be related to data on the deposition medium and thermal history of the sediment. For such studies the selectivity is obviously the main concern if the extract amounts are sufficient to be studied by gas chromatography-mass spectrometry (GC-MS).

However, obtaining the extracts using the above procedures is time-consuming and requires the use of large volumes of flammable solvents, which creates disposal problems. Therefore, the use of supercritical fluids and liquids with higher than normal vapour pressures as extractants has opened up a new dimension in separation science (refs. 1 and 2 and references therein). Those fluids are faster, more economical and usually more efficient.

Supercritical carbon dioxide extraction (SFE) of coals and source rocks and its comparison with other conventional methods have been reported in the literature [3]. The advantages of the SFE are obvious and have often been described, but the availability of the necessary instrumentation still prevents the wider use of this technique.

As an alternative to extracting semivolatile and high-molecular-mass organic compounds from similar raw materials, we have used in our work a single and cost-effective apparatus that permits the use of liquid carbon dioxide under liquid-vapour conditions, previously used for extracting plant materials [1]. Both the yields of the extractions and the composition of the extracts as determined by GC-MS were compared with those obtained by extraction in Soxhlet with $n$-hexane (Merck, Darmstadt, Germany).

\section{EXPERIMENTAL}

The samples of peat and coal were taken from two closely sited deposits at Padul and Arenas del Rey (Granada, Spain), and the bituminous oil shale was from the Puertollano Basin (Ciudad Real. 
Spain). The main geological characteristics of the deposits, as well as the geochemical features of the samples, have been published elsewhere $[4,5]$. Before extraction, the samples were dried, milled and weighed in extraction cartridges.

An apparatus of the Jennings type [6] modified by Lentz [7] was used for the carbon dioxide extraction. The most important technical features have been described elsewhere [1]. Briefly, the high-pressure part consisted of a cylindrical autoclave of stainless steel. The top enclosure contained a cooling finger, a gauge and a valve for loading and discharging the carbon dioxide. The inner extraction apparatus consisted of a glass extraction thimble with a siphon and a separate glass vessel serving as reservoir for the evaporating extractant and for the storage of the extract. The apparatus has to operate in the two-phase region below the critical temperature. Hence temperature and pressure have to be below the critical values of $31.3^{\circ} \mathrm{C}$ and $7.39 \mathrm{MPa}$. As the temperature is influenced by the temperature of the coolant circulating in the cooling finger, we had to use cooling equipment. To ensure evaporation of the extractant, the bottom of the apparatus was kept in a water bath at $40^{\circ} \mathrm{C}$. Carbon dioxide (Sociedad Española de Oxigeno, Spain) of $99.98 \%$ purity was transferred as a liquid from the storage vessel to the autoclave. The amount (around $180 \mathrm{~g}$ ) was controlled by weighing the whole autoclave on normal scales.

The Soxhlet extraction was carried out with $n$ hexane, which is a solvent similar to the carbon dioxide in terms of solubility parameters [3] under the above working conditions (critical density of $0.468 \mathrm{~g} / \mathrm{cm}^{3}$ ).

GC-MS analysis was performed with a HewlettPackard (Palo Alto, CA, USA) 5988A interfaced to an HP 59979 data system. A $25 \times 0.32 \mathrm{~mm}$ HPSE-52 capillary column was used with temperature programming to separate the extracted analytes.

\section{RESULTS AND DISCUSSION}

As shown in Fig. 1 the total ion chromatograms (TICs) of the carbon dioxide extracts of the oil shale (Fig. 1b), the peat (Fig. 1c) and the low-rank coal (Fig. 1d) are very complex, as is usual for the bituminous fraction from this type of sample. Greater
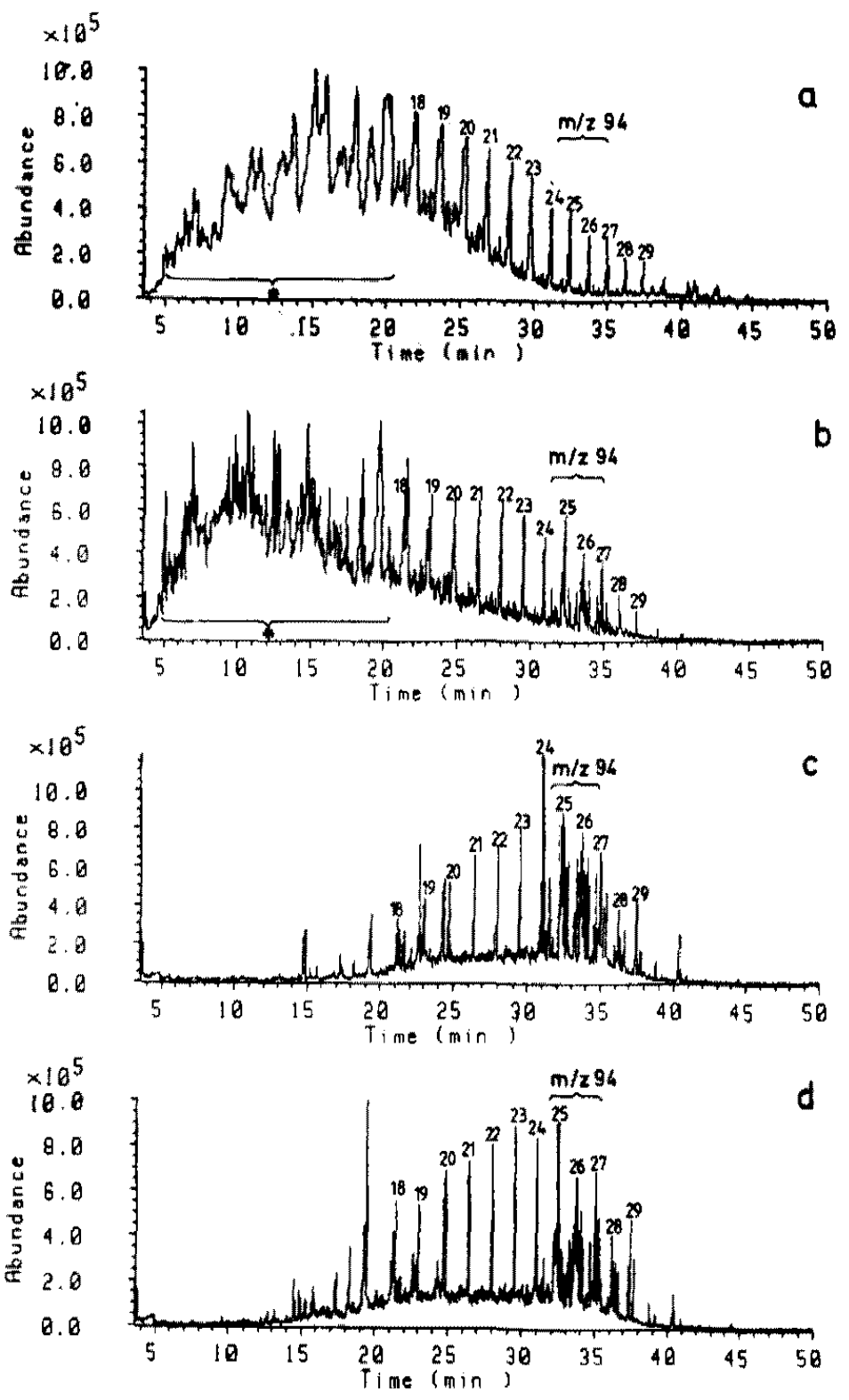

Fig. 1. Total ion chromatograms (TICs) of the $n$-hexane extraction of an oil shale (a) and the liquid carbon dioxide extracts from the same oil shale (b), a peat (c) and a low-rank coal (d). Peaks at $\mathrm{m} / \mathrm{z} 94$ represent artefacts introduced by the carbon dioxide. Numbers correspond to the chain lengths of $n$-alkanes. Most of the compounds marked with asterisks in (a) and (b) have been identified as series of alkyl cyclohexanes and bicyclic hydrocarbons.

similarity is apparent between the patterns of the samples of peat and low-rank coal than between these and that of the oil shale sample, in agreement with data previously obtained [5].

For comparative purposes the TICs of the Soxhlet $n$-hexane extract of the oil shale have been also included in the same figure (Fig. 1a). No great differences (less than 10\%) in extraction yield were observed considering the same extraction time $(1 \mathrm{~h})$. Furthermore, the hydrocarbon patterns were equiv- 
alent for both methods, although some differences were apparent. Thus, the recovery of light hydrocarbons is better by liquid carbon dioxide extraction, and some individual components are present in different amounts in each chromatogram.

Most of the peaks in each TIC could be identified by different procedures, including the monitoring of single diagnostic ions (SIMs) for some series present in small amount. The chemical nature of the most important homologous series detected is described in the caption to Fig. 1.

The most prominent peaks were series of $n$-alkanes in the range $\mathrm{C}_{14}-\mathrm{C}_{32}$ for all the samples, although with different distributions. They are wellknown biomarkers for evaluating the degree of maturity and the redox conditions during the diagenesis of the sediments.

In all the samples, series of branched alkanes of isoprenoid type in the range $\mathrm{C}_{14}-\mathrm{C}_{18}$, as well as polycyclic hydrocarbons from sesquiterpanes to tricyclic terpanes, were also detected. Only in the oil shale extracts, both with $n$-hexane and liquid carbon dioxide, were alkyl cyclohexanes $\left(\mathrm{C}_{4}-\mathrm{C}_{10}\right)$ and some single aromatic compounds (mono- and dimethylbenzenes) found in the zone marked with asterisks in the TICs.

The distributions of all these compounds have also been widely used for the organic geochemical characterization of recent and ancient sediments.

Some dialkyl phthalates, well-known ubiquitous contaminants, were also detected in all the extracts. In addition, the carbon dioxide used introduced some artefacts (marked with their typical base peak at $m / z 94$ on the TICs), tentatively identified as benzyl derivatives of the carbonic acid. One representative mass spectrum is shown in Fig. 2. In any case, these compounds did not interfere in the detection of biomarker hydrocarbons.

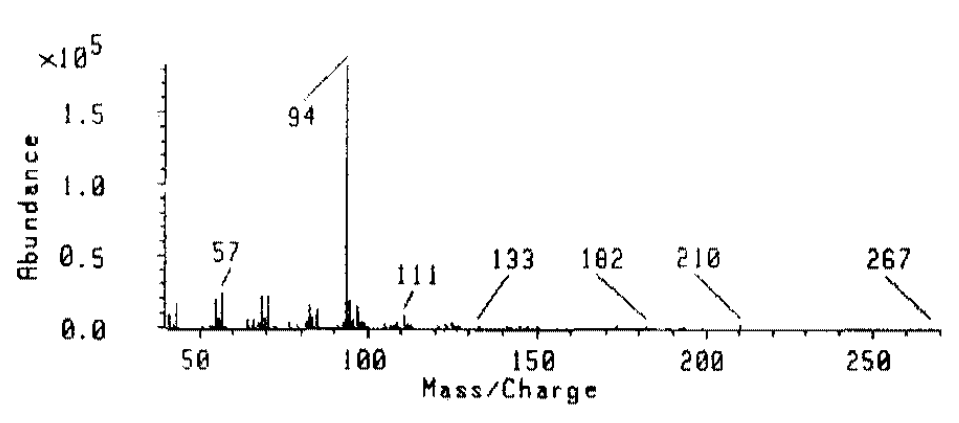

Fig. 2. Representative mass spectrum of one of the artifacts introduced by the carbon dioxide.

\section{CONCLUSIONS}

Although the organic geochemical significance of the differences found by comparing the different chromatographic extraction patterns, particularly the modifications of well-known compound ratios, should be evaluated with a wider set of samples, we can conclude that extraction with liquid carbon dioxide is a rapid, mild and clean procedure to study the biomarker composition of sedimentary organic matter.

\section{ACKNOWLEDGEMENT}

We thank the Spanish CICyT (Project PB 87/ 0277) for financial support.

\section{REFERENCES}

1 S. N. Naik, H. Lenz and R. C. Maheshwari, Fluid Phase Equilib., 49 (1989) 115.

2 M. Richards and R. M. Campbell, $L C \cdot G C$ Int., 4, No. 7 (1991) 33.

3 J. C. Monin, D. Barth, M. Perrut, M. Espitalié and B. Durand, Org. Geochem., 13 (1988) 1079.

4 J. C. del Rio, F. J. Gonzalez-Vila and F. Martin, Org. Geochem., 18 (1992) 67.

5 J. C. del Rio, J. Garcia-Molla, F. J. Gonzalez-Vila and F. Martin, Org. Geochem., 1992, submitted for publication.

6 W. G. Jennings, US Pat. 4.265 .860 (1981).

7 H. Lentz, German Utility Pat. G 8810807.4 (1988). 